\title{
Effect of Deposition Time on the Photoelectrochemical Properties of Cupric Oxide Thin Films Synthesized via Electrodeposition Method
}

\author{
Chong Siang Yaw ${ }^{1}$, Ai Kah Soh ${ }^{2}$, Meng Nan Chong ${ }^{1,3}$ \\ ${ }^{1}$ School of Engineering, Chemical Engineering Discipline, Monash University Malaysia, Jalan Lagoon Selatan, Bandar Sunway, Selangor \\ DE 47500 Malaysia \\ ${ }^{2}$ School of Engineering, Mechanical Engineering Discipline, Monash University Malaysia, Jalan Lagoon Selatan, Bandar Sunway, \\ Selangor DE 47500 Malaysia
}

${ }^{3}$ Sustainable Water Alliance, Advanced Engineering Platform, Monash University Malaysia, Jalan Lagoon Selatan, Bandar Sunway, Selangor DE 47500 Malaysia

\begin{abstract}
The main aim of this study was to investigate the effect of deposition time on the physicochemical and photoelectrochemical properties of cupric oxide $(\mathrm{CuO})$ thin films synthesized via electrodeposition method. Firstly, the electrodeposition of amorphous $\mathrm{CuO}$ films on fluorine-doped tin oxide (FTO) working electrodes with varying deposition time between 5 and $30 \mathrm{~min}$ was carried out, followed by annealing treatment at $500{ }^{\circ} \mathrm{C}$. Resultant nanocrystalline $\mathrm{CuO}$ thin films were characterised using field emission-scanning electron microscopy (FE-SEM), photocurrent density, and photoluminescence measurements. Through FE-SEM analysis, it was observed that the surface of thin films was composed of irregular-sized $\mathrm{CuO}$ nanocrystals. A smaller $\mathrm{CuO}$ nanocrystals size will lead to a higher photoactivity due to the increase in overall catalytic surface area. In addition, the smaller $\mathrm{CuO}$ nanocrystals size will prolongs the electron-hole recombination rate due to the increase in copious amount of surface defects. From this study, it was revealed that the relationship between deposition time and $\mathrm{CuO}$ film thickness was non-linear. This could be due to the detachment of $\mathrm{CuO}$ thin films from the FTO surface at an increasing amount of $\mathrm{CuO}$ mass being deposited. It was observed that the amount of light absorbed by $\mathrm{CuO}$ thin films increased with film thickness until a certain extent whereby, any further increase in the film thickness will result in a reduction of light photon penetration. Therefore, the $\mathrm{CuO}$ nanocrystals size and film thickness have to be compromised in order to yield a higher catalytic surface area and a lower rate of surface charge recombination. Finally, it was found that the deposition time of 15 min resulted in an average $\mathrm{CuO}$ nanocrystals size of $73.7 \mathrm{~nm}$, optimum film thickness of $0.73 \mu \mathrm{m}$, and corresponding photocurrent density of $0.23 \mathrm{~mA} / \mathrm{cm}^{2}$ at the potential bias of $-0.3 \mathrm{~V}$ (versus $\mathrm{Ag} / \mathrm{AgCl}$ ). The PL spectra for the deposition time of $15 \mathrm{~min}$ has the lowest rate of recombination of photogenerated electron-hole pairs by referring to its lowest PL intensity.
\end{abstract}

\section{Introduction}

Photoelectrochemical (PEC) water splitting is a photodriven conversion process of water molecules into hydrogen and oxygen molecules through the use of semiconductor metal oxides photocatalysts [1]. In a PEC cell, minority charge carriers will be generated when the amount of light photons being absorbed by the semiconductor photocatalyst used is greater than its corresponding bandgap energy level [2]. Therefore, the type of semiconductor photocatalysts used in the PEC water splitting process will affect the efficiency of waterto-hydrogen conversion process due to their inherent bandgap characteristics.
To date, the synthesis of nanostructured semiconductor metal oxides photocatalysts have attracted much attention due to their promising properties in different fields of application ranging from sensors, optoelectronics, and electronics to catalysis. Binary copper semiconductors have attracted much research interests owing to their high photoactivity, inexpensive and that copper is a relatively abundant element [2]. Cupric oxide $(\mathrm{CuO})$ is one of the $p$-type binary copper semiconductors with a narrow bandgap of 1.3 to $1.9 \mathrm{eV}$, and a corresponding theoretical photocurrent density of $35 \mathrm{~mA} / \mathrm{cm}^{2}[3,4]$.

The physical and chemical properties of $\mathrm{CuO}$ thin films are strongly dependent on the method of preparation. There are various synthesis methods used to 
synthesize $\mathrm{CuO}$ thin films, such as pulsed laser deposition [5], electrodeposition [6], chemical vapor deposition [7], and sol-gel method [8]. Among all, electrodeposition is a simple and straightforward method that can be operated at ambient operating pressure and temperature, as well as being an inexpensive method. The electrodeposition method is also enabling the direct control of film thickness by systematically manipulating the synthesis parameters [9]. It was reported that controlling the $\mathrm{CuO}$ film thickness could have a profound effect on the photocurrent density, and subsequently leading to a higher efficiency in the water-to-hydrogen conversion process [10].

Previously, Patake et al. [11] have prepared porous and amorphous $\mathrm{CuO}$ thin films via cathodic electrodeposition method, and subsequently studied for their potential application as supercapacitor and their characteristics. Lim et al. [4] studied the deposition of $\mathrm{Cu}_{2} \mathrm{O}$ and $\mathrm{CuO}$ thin films by a sol-gel spin-coating process, and enhanced the PEC performance by depositing a thin layer of $\mathrm{NiO}_{\mathrm{x}}$ co-catalyst. Wang et al. [6] investigated the effect of deposition voltage on the morphology of $\mathrm{CuO}$ thin films. Although these previous studies have discussed on the growth, characterisation and application of $\mathrm{CuO}$ thin films, there is less information available that detailed on the relationship between deposition time, nanocrystals size, film thickness, and photocurrent density.

Thus, the main aim of this study was to systematically investigate the effect of deposition time on the physicochemical and $\mathrm{PEC}$ properties of $\mathrm{CuO}$ thin films synthesized via electrodeposition method. Initially, the $p$-type $\mathrm{CuO}$ thin films of different film thicknesses were synthesized on fluorine-doped tin oxide (FTO) working electrodes by varying the deposition time between 5 and $30 \mathrm{~min}$, followed by annealing treatment at $500{ }^{\circ} \mathrm{C}$. The resultant $p$-type $\mathrm{CuO}$ thin films were further characterised using field emission-scanning electron microscopy (FE-SEM), photocurrent density, and photoluminescence (PL) measurements.

\section{Materials and methods}

Materials. Copper (II) sulphate $\left(\mathrm{CuSO}_{4}\right)$, di-potassium hydrogen phosphate $\left(\mathrm{K}_{2} \mathrm{HPO}_{4}\right)$, potassium hydroxide $(\mathrm{KOH})$, lactic acid $\left(\mathrm{C}_{3} \mathrm{H}_{6} \mathrm{O}_{3}\right)$, and sodium sulfate $\left(\mathrm{Na}_{2} \mathrm{SO}_{4}\right)$ were purchased from Merck Malaysia. All the reagents are of analytical grade and used without further purification.

Preparation of $\mathrm{CuO}$ thin films. Electrodeposition of $\mathrm{CuO}$ thin films was carried out in a three-electrode PEC cell that comprised of FTO, a platinum (Pt) rod, and a saturated silver/silver chloride $(\mathrm{Ag} / \mathrm{AgCl})$ electrode used as the working, counter, and reference electrodes, respectively. Before the electrodeposition synthesis process, FTO glass slides (ChemSoln, USA; resistivity of
$14 \Omega / \mathrm{sq}$ ) were cleaned ultrasonically using acetone, ethanol, and deionised water for $20 \mathrm{~min}$, before being dried in the oven. The electrolyte used for the electrodeposition synthesis process was made up of $0.2 \mathrm{M}$ $\mathrm{CuSO}_{4}$ and $3 \mathrm{M}$ lactic acid solution in deionised water with $0.5 \mathrm{M} \quad \mathrm{K}_{2} \mathrm{HPO}_{4}$ buffer. Following this, the electrodeposition process was carried out at $\mathrm{pH} 9$ by adjusting the $\mathrm{pH}$ of the solution using $2 \mathrm{M} \mathrm{KOH}$. The electrodeposition synthesis process was conducted potentiostatically with an applied potential of $-0.4 \mathrm{~V}$ versus $\mathrm{Ag} / \mathrm{AgCl}$. The deposition time was varied between 5 and $30 \mathrm{~min}$. After the electrodeposition process, the FTO glass slides were washed with deionised water to remove the presence of any ion followed by annealing treatment at $500{ }^{\circ} \mathrm{C}$ for $30 \mathrm{~min}$.

Characterisation of $\mathrm{CuO}$ thin films. Different thicknesses of $\mathrm{CuO}$ thin films were examined using FESEM (FEI Nova NanoSEM; accelerating voltage $1 \mathrm{kV}$ ). Photocurrent density measurements were carried out in a standard three-electrode assembly using an applied potentiostat/galvanostat (Metrohm PGSTAT 204 model, Netherlands). Similarly, the saturated $\mathrm{Ag} / \mathrm{AgCl}$ electrode and $\mathrm{Pt}$ rod were used as the reference and counter electrodes, respectively. The photocurrent density measurements were conducted inside a dark box at room temperature. A $100 \mathrm{~W}$ halogen lamp restricted at a frequency of $0.05 \mathrm{~Hz}$ was used as the light source during the photocurrent density measurements. The intensity of incident light flux was measured using a digital light meter to be $8700 \mathrm{~mW} / \mathrm{m}^{2}$ at a light source-to-sample distance of $10 \mathrm{~cm}$. The FTO working electrode was estimated to be approximately $1.32 \mathrm{~cm}^{2}$. All the photocurrent experiments were conducted in a $0.5 \mathrm{M}$ aqueous $\mathrm{Na}_{2} \mathrm{SO}_{4}$ solution. PL measurements were carried out using a fluorescence spectrophotometer (LS 55, Perkin Elmer) at room temperature. The excitation wavelength was $325 \mathrm{~nm}$ with a scanning speed of 500 $\mathrm{nm} / \mathrm{min}$, while the emission spectra were scanned from 600 to $700 \mathrm{~nm}$.

\section{Results and Discussion}

FE-SEM.

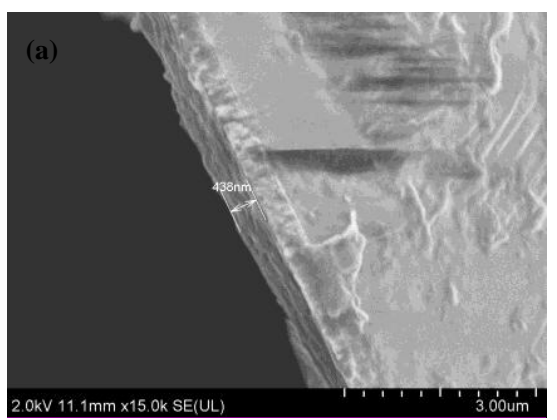




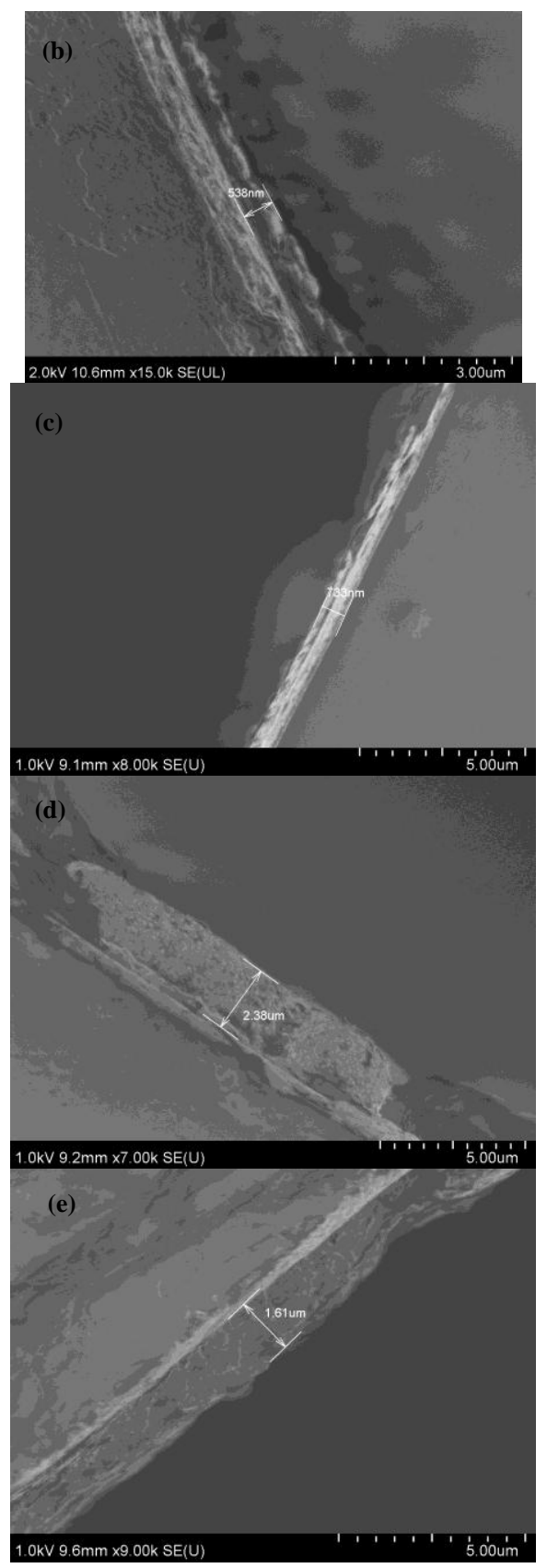

Figure 1. Cross-sectional FE-SEM images of $\mathrm{CuO}$ thin films at different deposition time of: (a) $5 \mathrm{~min}$; (b) $10 \mathrm{~min}$; (c) $15 \mathrm{~min}$; (d) $20 \mathrm{~min}$ and ; (e) $30 \mathrm{~min}$.

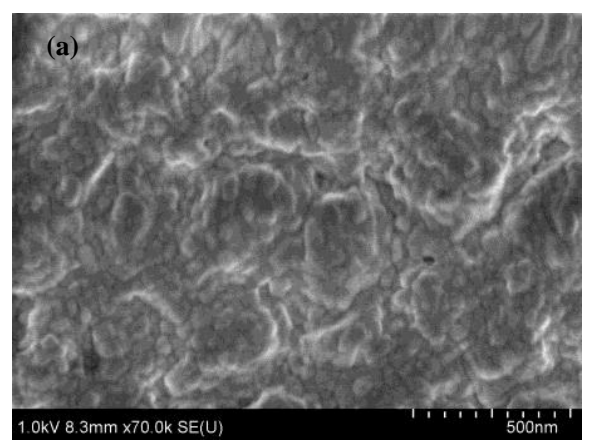

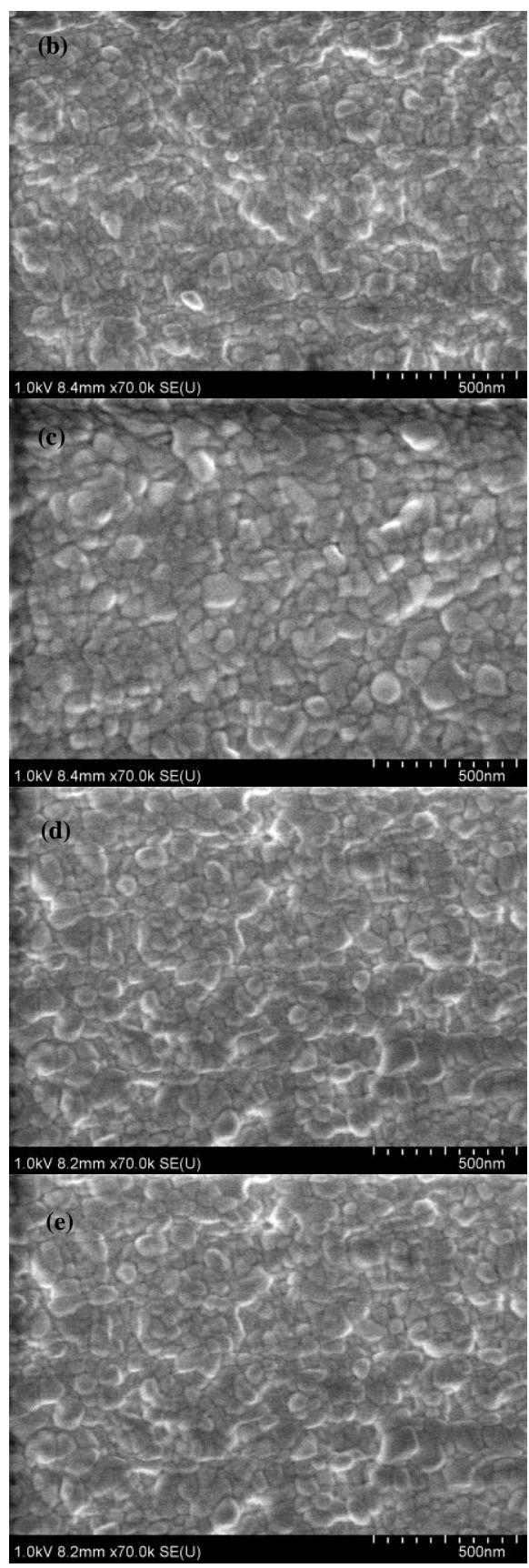

Figure 2. Top view FE-SEM images of $\mathrm{CuO}$ thin films at different deposition time of: (a) $5 \mathrm{~min}$; (b) $10 \mathrm{~min}$; (c) $15 \mathrm{~min}$; (d) $20 \mathrm{~min}$ and; (e) $30 \mathrm{~min}$.

Table 1. Relationship between deposition time, $\mathrm{CuO}$ film thickness and nanocrystals size.

\begin{tabular}{|c|c|c|}
\hline $\begin{array}{c}\text { Deposition time } \\
(\mathrm{min})\end{array}$ & $\begin{array}{c}\text { Film thickness } \\
(\mu \mathrm{m})\end{array}$ & $\begin{array}{c}\text { Nanocrystals } \\
\text { size }(\mathrm{nm})\end{array}$ \\
\hline 5 & 0.43 & 53.8 \\
\hline 10 & 0.56 & 74.6 \\
\hline 15 & 0.73 & 73.7 \\
\hline 20 & 2.57 & 74.0 \\
\hline 30 & 1.61 & 83.6 \\
\hline
\end{tabular}

Figure 1 and 2 show the FE-SEM images used to determining the $\mathrm{CuO}$ film thickness and nanocrystals size at varying deposition time. From the FE-SEM images, it 
was observed that the surface of thin films is composed of irregular-sized $\mathrm{CuO}$ nanocrystals. Moreover, it was observed that the longer the deposition time, the rougher the $\mathrm{CuO}$ film surface. This is expected because the larger the $\mathrm{CuO}$ grains size will results in a rougher surface. Table 1 shows how the variation in deposition time affects the $\mathrm{CuO}$ film thickness and nanocrystals size. From Table 1, it was observed that $\mathrm{CuO}$ films with different thicknesses were synthesized by effectively manipulating the deposition time. Generally, the $\mathrm{CuO}$ film thickness was found to increase with increasing deposition time due to that more $\mathrm{Cu}^{2+}$ ions being diffused to the FTO surface, underwent reduction reaction, and subsequently deposited on it as shown in Eq. (1).

$$
2 \mathrm{Cu}^{2+}+\mathrm{H}_{2} \mathrm{O}+2 \mathrm{e}^{-} \rightarrow \mathrm{Cu}_{2} \mathrm{O}+2 \mathrm{H}^{+}
$$

However, the relationship between deposition time and $\mathrm{CuO}$ film thickness was non-linear. It was observed that the $\mathrm{CuO}$ film thickness decreased when the deposition time was increased to more than $20 \mathrm{~min}$. This could be due to the porous structure formation of $\mathrm{CuO}$ films, and caused the falling-off of porous deposits [1]. On the other hand, the $\mathrm{CuO}$ nanocrystals size was found to increase with increasing deposition time. This trend is expected due to the coalescence of growing $\mathrm{CuO}$ grains after they have attained a given size.

\section{Photocurrent Density Measurements.}

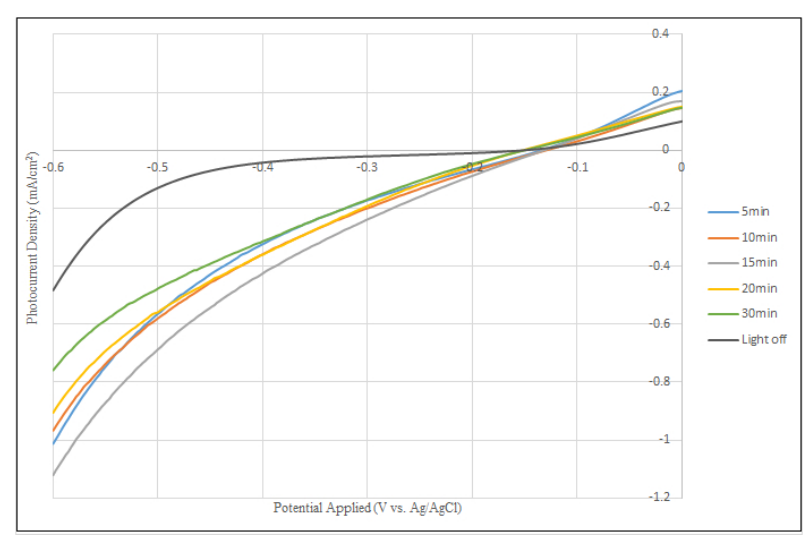

Figure 3. Photocurrent density profiles for $\mathrm{CuO}$ thin films under dark and irradiated conditions.

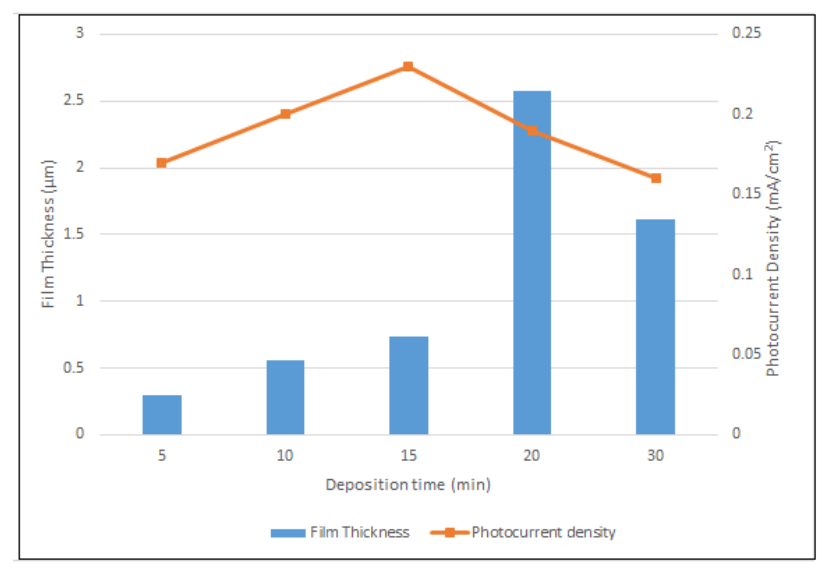

Figure 4. Effect of deposition time on $\mathrm{CuO}$ film thickness and photocurrent density.
Figure 3 shows the photocurrent density profiles for $\mathrm{CuO}$ thin films under dark and irradiated conditions. As the potential swept towards the negative direction from $0 \mathrm{~V}$ to $-0.6 \mathrm{~V}$ (vs. $\mathrm{Ag} / \mathrm{AgCl}$ ), cathodic photocurrents were observed. Generally, the photocurrent density of $\mathrm{CuO}$ thin films is increasing with the increase in applied potential. This is due to the higher band-bending at the working electrode/electrolyte interface, which leads to a higher mobility of the photogenerated excitons and expansion of the depletion width with increasing applied potential [2]. In this study, the potential bias of $-0.3 \mathrm{~V}$ (vs. $\mathrm{Ag} / \mathrm{AgCl}$ ) on the $\mathrm{CuO}$ thin films was used for the comparison of photocurrent density for different $\mathrm{CuO}$ thin films formed under varying deposition time. From Figure 4, it can be seen that the photocurrent density of $\mathrm{CuO}$ thin films increased with increasing film thickness. This could be due to the formation of steep band bending that enhances the charge separation of electrode and reduced carrier recombination in the bulk [3]. However, the photocurrent density started to decrease when the deposition time used was more than $15 \mathrm{~min}$. As the $\mathrm{CuO}$ film thickness increases, more light can be absorbed until a certain thickness, whereby the $\mathrm{CuO}$ films will reduce the light photon penetration. This will increase the electron-hole pair recombination rate and results in a lower water-to-hydrogen conversion efficiency [4].

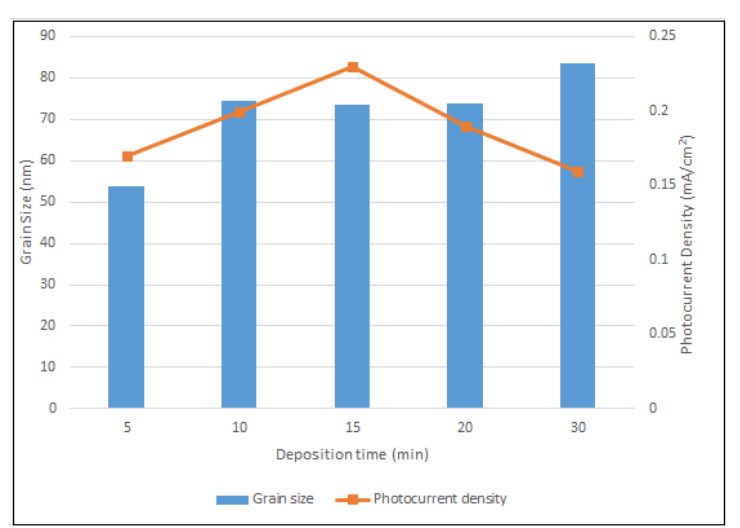

Figure 5. Effect of deposition time on $\mathrm{CuO}$ nanocrystals size and photocurrent density.

From Figure 5, it was found that the photocurrent density increased with increasing $\mathrm{CuO}$ nanocrystals size. It was observed that the $\mathrm{CuO}$ nanocrystals size remained almost constant for the depositon time of $10-20 \mathrm{~min}$, while the corresponding photocurrent densities varied. Therefore, it can be concluded that the change in the photocurrent densities was not solely due to the change in $\mathrm{CuO}$ nanocrystals size. The photocurrent density started to decrease when the $\mathrm{CuO}$ nanocrystals size was larger than $73.7 \mathrm{~nm}$. This observation could be explained by the larger $\mathrm{CuO}$ nanocrystals size and correspondingly lower catalytic surface area. This will result in a longer average minority carrier transport distance to the electrolyte interface and therefore, lower the collection efficiency.

\section{Photoluminescence Measurements.}

PL quenching effect is an efficient method to understand the emission mechanism and the charge transfer of the 
material. The PL intensity is representing the rate of recombination of photogenerated electron-hole pairs. Therefore, a lower PL intensity indicates that more photoinduced electrons are trapped and stably transferred through the interface. Otherwise, the more intense PL spectrum dictates the fast recombination rate of electronhole pairs. Figure 6 shows the PL spectra of $\mathrm{CuO}$ thin films synthesized at varying deposition time of 5 - $30 \mathrm{~min}$. It was found that the PL spectra are composed of a sharp emission peak in the red region $(662 \mathrm{~nm})$. The emission peak at $662 \mathrm{~nm}$ arises due to the band-to-band transition of $\mathrm{CuO}$ and other defects arising in the nanostructured mixture. The PL spectra for the deposition time of $15 \mathrm{~min}$ has the lowest rate of recombination of photogenerated electron-hole pairs by referring to its lowest intensity shown in Figure 6. A further comparison study of PL data and the photocurrent density measurements showed that the obtained results are consistent with each other.

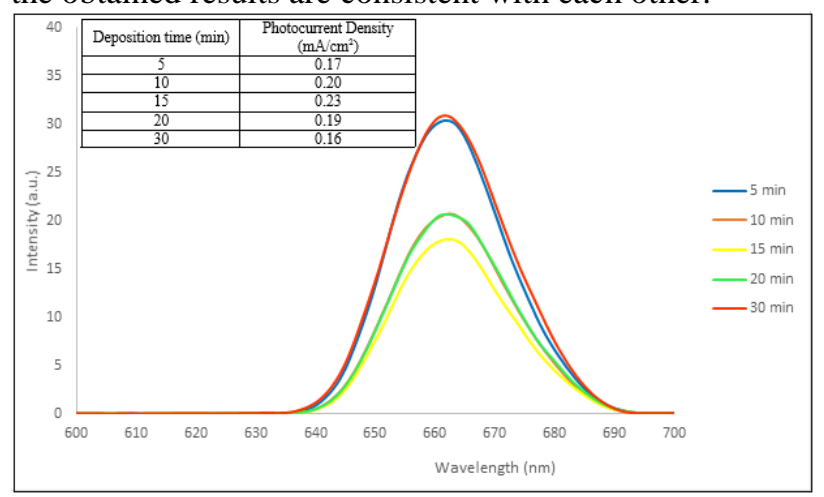

Figure 6. PL measurements of $\mathrm{CuO}$ thin films at different deposition time.

\section{Conclusion}

In conclusion, the effect of deposition time on the physicochemical and PEC properties of $\mathrm{CuO}$ thin films synthesized via electrodeposition method was systematically investigated. A smaller $\mathrm{CuO}$ nanocrystals size will lead to a higher photoactivity due to the increase in overall catalytic surface area. In addition, the smaller $\mathrm{CuO}$ nanocrystals size will prolongs the electron-hole recombination rate due to the increase in copious amount of surface defects. From this study, it was revealed that the relationship between deposition time and $\mathrm{CuO}$ film thickness was non-linear. This could be due to the detachment of $\mathrm{CuO}$ thin films from the FTO surface at an increasing amount of $\mathrm{CuO}$ mass being deposited. It was observed that the amount of light absorbed by $\mathrm{CuO}$ thin films increased with film thickness until a certain extent whereby, any further increase in the film thickness will result in a reduction of light photon penetration. Therefore, the $\mathrm{CuO}$ nanocrystals size and film thickness have to be compromised in order to yield a higher catalytic surface area and a lower rate of surface charge recombination. Finally, it was found that the deposition time of $15 \mathrm{~min}$ resulted in an average $\mathrm{CuO}$ nanocrystals size of $73.7 \mathrm{~nm}$, optimum film thickness of $0.73 \mu \mathrm{m}$, and corresponding photocurrent density of $0.23 \mathrm{~mA} / \mathrm{cm} 2$ at the potential bias of $-0.3 \mathrm{~V}$ (versus $\mathrm{Ag} / \mathrm{AgCl}$ ). The PL spectra for the deposition time of $15 \mathrm{~min}$ has the lowest rate of recombination of photogenerated electron-hole pairs by referring to its lowest PL intensity.

\section{Acknowledgement}

The authors are grateful to the financial support provided by the Fundamental Research Grant Scheme (FRGS) (Project Reference Code : FRGS/1/2014/SG06/MUSM/02/1) from Ministry of Education (MOE), Malaysia. Similar gratitude also goes to the Advanced Engineering Platform, Monash University Malaysia.

\section{References}

1. Zhu. T, M.N. Chong, and E.S. Chan, Nanostructured tungsten trioxide thin films synthesized for photoelectrocatalytic water oxidation: a review. ChemSusChem, 7, 11 (2014): p. 2974-2997.

2. A. Paracchino, V. Laporte, K. Sivula, M. Gratzel, E. Thimsen, Highly active oxide photocathode for photoelectrochemical water reduction. Nature materials, 10, 6 (2011): p. 456-461.

3. M. Izaki, M. Nagai,K. Maeda, F. Mohamad, K. Motomura, J. Sasano, S. Watase, Electrodeposition of 1.4-eV-bandgap p-copper (II) oxide film with excellent photoactivity. Journal of The Electrochemical Society, 158, 9 (2011): p. D578-D584.

4. Y.F. Lim, C.S. Chua, C.J.J. Lee, D. Chi, Sol-gel deposited $\mathrm{Cu}_{2} \mathrm{O}$ and $\mathrm{CuO}$ thin films for photocatalytic water splitting. Physical Chemistry Chemical Physics, 2014. 16, 47 (2014): p. 25928-25934.

5. A. Chen, H. Long, X. Li, Y. Li, G. Yang, P. Lu, Controlled growth and characteristics of single-phase $\mathrm{Cu}_{2} \mathrm{O}$ and $\mathrm{CuO}$ films by pulsed laser deposition. Vacuum, 83, 6 (2009): p. 927-930.

6. Y. Wang, T. Jiang, D. Meng, J. Yang, Y. Lim Q. $\mathrm{Ma}$, J. Han, Fabrication of nanostructured $\mathrm{CuO}$ films by electrodeposition and their photocatalytic properties. Applied Surface Science, 317 (2014): p. 414-421.

7. M.R. Johan, M.S.M. Suan, N.L. Hawari, H.A. Ching, Annealing effects on the properties of copper oxide thin films prepared by chemical deposition. Int. J. Electrochem. Sci, 6 (2011): p. 6094-6104.

8. Akhavan, O. and E. Ghaderi, $\mathrm{Cu}$ and $\mathrm{CuO}$ nanoparticles immobilized by silica thin films as antibacterial materials and photocatalysts. Surface and Coatings Technology, 205, 1 (2010): p. 219-223.

9. S. Wei, Y. Ma, Y. Chen, L. Liu, Z. Shao, Fabrication of $\mathrm{WO}_{3} / \mathrm{Cu}_{2} \mathrm{O}$ composite films and their photocatalytic activity. Journal of hazardous materials, 194 (2011): p. 243-249.

10. S. Ito, S.M. Zakeeruddin, R. Humphry-Baker, P. Liska, R. Charvet, P. Comte, M.K. Nazeeruddin, P. Pechy, M. Takata, H. Miura,High-Efficiency Organic-Dye-Sensitized Solar Cells Controlled by Nanocrystalline- $\mathrm{TiO}_{2}$ Electrode Thickness. Advanced Materials, 18,9 (2006): p. 1202-1205.

11. V. Patake, S. Joshim C. Lokhande, O.S. Joo, Electrodeposited porous and amorphous copper oxide film for application in supercapacitor. Materials Chemistry and Physics, 2009. 114, 1 (2009): p. 6-9.

12. Kwong, W., N. Savvides, and C. Sorrell, Electrodeposited nanostructured $\mathrm{WO}_{3}$ thin films for 
photoelectrochemical applications. Electrochimica Acta, 75 (2012): p. 371-380.

13. M. Takahashi, K. Tsukigi, T. Uchino, T. Yoko, Enhanced photocurrent in thin film $\mathrm{TiO}_{2}$ electrodes prepared by sol-gel method. Thin Solid Films, 2001. 388, 1 (2001): p. 231-236.

14. K.R. Lee, Y.P. Hsu, J.L. Chang, S.W. Lee, C.J. Tseng, J.S.C. Jang, Effects of Spin Speed on the Photoelectrochemical Properties of $\mathrm{Fe}_{2} \mathrm{O}_{3}$ Thin Films. Int.

J. Electrochem. Sci, 9 (2014): p. 7680-7692. 